\title{
In Silico prediction and Comparative Modeling of proteins in Creeping Fig (Ficus pumila) plant
}

\section{P. REVATHI ${ }^{\mathrm{a} *}$, K. NIRUBAMA $^{\mathrm{b}}$, G. THAMOTHARAN $^{\mathrm{c}}$ AND M. BEUTLINE MALGIJA ${ }^{\mathrm{d}}$}

${ }^{a}$ Department of Botany, Kongunadu Arts and Science College, Coimbatore-641029, Tamil Nadu, India ${ }^{\mathrm{b}}$ Department of Biochemistry, Kongunadu Arts and Science College, Coimbatore-641029, Tamil Nadu, India ${ }^{c}$ Department of Pharmacology, JKKMMRF College of Pharmacy, Komarapalayam,Tamil Nadu, India ${ }^{\mathrm{d}}$ Bioinformatics Centre of BTISnet, Madras Christian College, Chennai, Tamil Nadu, India

*Address for Correspondence

Dr. P. Revathi,

PG and Research Department of Botany,

Kongunadu Arts and Science College (Autonomous),

Coimbatore- 641029.

E-mail: revathip_bo@kongunaducollege.ac.in; reva.ponnusamy@gmail.com

Mob.: +919578580628

\section{ABSTRACT}

In the present study, the Ficus pumila have taken to analyze the proteins by their preliminary characters from the database and predicted vital role of different sequences. The F. pumila (Creeping fig) is a prostrate/climbing shrub, experiments proved various active phytochemicals and antioxidant, antimicrobial, antimutagenic, analgesic, anti-inflammatory, antiproliferative, hypoglycemic, hypolipidemic, anti-hyperprolactinemic, anticholinesterase, nephroprotective properties. In addition to all metabolites, it also constitutes specific proteins that were evaluated through insilico homology modeling. Though it is considered as a poisonous weed, the protein present in this plant is evaluated by physicochemical, phylogeny and amino acid proportions by protparam, Swiss model, SOPMA, Clustal omega tools to describe its structural features and to understand molecular function. The computed theoretical isoelectric point (pI) found to be more than 7 indicates basic nature of proteins. The aliphatic index ranges 67-113 indicates thermal stability of proteins. The predicted Grand average hydropathy(GRAVY) shows possibilities of enhanced interaction of these proteins with water by lowest value. Functional analysis of these proteins was performed by SOSUI server which predicted transmembrane helix and solubility. Secondary structure analysis was carried out by SOPMA revealed that Alpha helix and random coil dominated followed by extended strand, and beta turns among secondary structure elements. The modelling of three-dimensional structure of proteins was performed by Swiss model. The model was validated using protein structure checking tool- VADAR. Particularly, NAD(P)H quinoneoxidoreductase and Glyceraldehyde-3-phosphate dehydrogenase structures were analysed by phylogenetic analysis to trace relationship and reported. The results suggesting its possible role in cellular and metabolic functions.

Keywords: $N A D(P) H$-quinone oxidoreductase; Glyceraldehyde-3-phosphate dehydrogenase; Ficus pumila; phylogeny; Plant protein; Phylogenetic analysis

\section{INTRODUCTION}

Recent advances in sequence analysis methods and software have revolutionized the characterization and phylogenetic studies ${ }^{[1]}$. The availability of structural models of proteins is the key to understanding biological processes at a molecular level. The lot of protein sequences that can be modeled, as well as the exactness of the prediction, is growing gradually because of the growth and number of known protein sequences and structures as well as advances in the modeling software ${ }^{[2]}$.

Sequence databases are of special importance for different fields of biological research because they are comprehensive sources of information on nucleotide sequences and proteins primary, secondary and tertiary characters. The tools for the computational analysis of the data and retrieved sequences are necessary resources for biological and medical research ${ }^{[3]}$. Plants are an abundant source of natural components especially proteins. In this study, proteins of $F$. 
pumila have been validated and expressed as preliminary characters of the same for the betterment of plant proteomic researches. Thus understanding its structural details would be a great revolution for engineering new herbicides, developing resistant crops and antimicrobial drugs ${ }^{[4]}$.

The Ficus species are used as food and as medication in traditional practices like Ayurveda, Siddha and Chinese Medicine. The $F$. pumila (Creeping fig) is a prostrate or climbing shrub, experiments proved various active phytochemicals like alkaloids, carbohydrates, tannins, flavonoids, saponin, glycosides, and steroid/triterpenoids ${ }^{[1]}$. The biological activities have proved through various experiments predominantly antioxidant, antimicrobial, antimutagenic, analgesic, anti-inflammatory, antiproliferative, hypoglycemic, hypolipidemic, anti-hyperprolactinemic, anticholinesterase, nephroprotective analytic methods. In addition to all metabolites, it also constitutes specific proteins that were evaluated in this attempt through Insilco homology modeling. Traditionally this plant is used for malaise, fever, shivering, and vomiting in New Guinea. In China and Japan, it has been using for rheumatism, arthritis and pains due to sprains and even to treat diabetes and high blood pressure ${ }^{[5]}$. The biologically active plant proteins need to get attention to acquaintance science and to make potential and sustainable alternative sources for various applications and essentials. This proteome is analyzable according to distribution of domains and protein families, and secondary and tertiary structures of proteins and can be made comparable to other proteomes ${ }^{[3]}$.

Despite progress in protein structure prediction, qualified modeling remains the only process that can constantly predict the 3-D structure of a protein with accuracy comparable to a low-resolution experimentally determined structure. Even models with mistakes may be useful because some features of function can be predictable from only coarse structural features ${ }^{[6]}$. The structures were taken to account along with phylogenetic analysis to trace the relationships.

\section{MATERIALS AND METHODS}

\section{Sequence Retrieval}

The FASTA sequences of the proteins were retrieved by using Genbank database hosted by the NCBI ${ }^{[7]}$.

\section{Primary Structure Prediction}

The Expasy Protparm server has been used to get the physiochemical properties of proteins such as theoretical Isoelectric Point (pI), molecular weight, total number of positive and negative residues, extinction coefficient, instability index(Ii), aliphatic index (Ai) and grand average of hydropathy (GRAVY) ${ }^{[8]}$.

\section{Structure Prediction}

SOPMA (Self Optimized Prediction Method with Alignment) was used for the secondary structure prediction. Swiss model and Phyre2 were used for tertiary structure prediction of the proteins.

\section{Functional Characterization}

SOSUI tool used to describe whether the protein is soluble or transmembrane in nature. InterPro is a combined resource for protein families, domains and functional sites. Inter Pro incorporates the major protein signature databases into a single resource. Superfamily and molecular function were predicted by Inter Proprotein sequencing and classification. Motif Search from Genome Net was used for predicting the functional domains.

Sequence alignment was performed using pairwise sequence alignment tool (NCBI- BLAST) (http://blast.ncbi.nlm.nih.gov/Blast.cgi) and multiple sequence alignment was done using the EBI-CLUSTAL OMEGA (http://www.ebi.ac.uk/Tools/msa/clustalo/) tool. This Clustal Omega has features for adding sequences to and exploiting information in existing alignments, making use of the vast amount of precomputed information in public databases like Pfam ${ }^{[9]}$. The importance of this work was to novelty the regions of sequence comparison, which in other words allows us to yield functional and evolutionary relationships among the proteins considered in this study.

The phylogenetic analysis of ten to twenty proteins with most similarity percentage was completed to determine the number of proteins that part common structural and functional features. As an input to Clustal Omega, all sequences in FASTA formats were supplied with default options. The output was analyzed for sequences and the phylogenetic tree was constructed based on the bootstrap Neighbour Joining (NJ) method ${ }^{[10]}$. The steadiness of the internal nodes was assessed by bootstrap analysis with 1000 replicates.

\section{RESULTS AND DISCUSSIONS}

To classify and trace out the evolutionary path among related species, it is important to investigate them at the molecular level for better understanding of the evolution of plants ${ }^{[11]}$.

Parameters computed using Expasy's ProtParam tool revealed that the highest molecular weight has observed as 45498 with the length of 424 in ATP synthase. It is also indicated that the pI of 5 proteins were less than 7, indicates those proteins were acidic (Table 1), from which pI of 2 proteins was nearly 7 ,

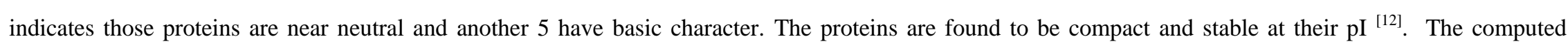
isoelectric point (pI) will be useful for developing a buffer system for purification by the isoelectric focusing method ${ }^{[13]}$. Except 3 , all the proteins of Ficus pumila showed instability index smaller than 40, which indicates the proteins are stable. The aliphatic index ranges from 67.41-112.02 indicates the thermal stability of the proteins. Grand average hydropathy (GRAVY) was predicted to be lower value shows the possibility of better interaction of these proteins with water ${ }^{[14]}$. The range of GRAVY of Ficus pumila proteins was -0.419 to 0.265 . 
Table 1: Accession numbers of the $F$. pumila proteins and physicochemical characters:

\begin{tabular}{|c|c|c|c|c|c|c|c|c|c|c|}
\hline Protein name & $\begin{array}{l}\text { Accession } \\
\text { No. }\end{array}$ & Length & Mol.Wt & pI & R- & $\mathbf{R}+$ & $\mathbf{E C}$ & Ii & AI & Gravy \\
\hline $\begin{array}{l}\text { NAD(P)H- } \\
\text { quinoneoxidoreductase } \\
\text { subunit }\end{array}$ & AAN63314.1 & 388 & 44707.60 & 9.59 & 20 & 35 & 68425 & 28.14 & 100.28 & 0.265 \\
\hline Chitinase & ABB86300.1 & 301 & 33233.09 & 5.74 & 31 & 25 & 48330 & 40.13 & 67.41 & -0.367 \\
\hline Oleosin & ABQ57397.1 & 153 & 16314.90 & 9.77 & 8 & 12 & 8480 & 44.58 & 108.43 & 0.159 \\
\hline $\begin{array}{l}\text { Glyceraldehyde-3- } \\
\text { phosphate } \\
\text { dehydrogenase }\end{array}$ & AEX08243.1 & 114 & 12039.58 & 6.48 & 14 & 14 & 8480 & 32.26 & 84.56 & -0.237 \\
\hline Cystatin & ACY30464.1 & 114 & 12821.06 & 9.67 & 9 & 15 & 24980 & 13.58 & 112.02 & 0.078 \\
\hline $\begin{array}{l}\text { Ribulose bisphosphate } \\
\text { carboxylase large } \\
\text { chain }\end{array}$ & AFJ76695.1 & 233 & 26036.51 & 6.93 & 29 & 29 & 39100 & 31.78 & 76.18 & -0.394 \\
\hline Maturase K & AFJ76529.1 & 265 & 31615.58 & 9.43 & 18 & 29 & 60070 & 39.02 & 87.51 & -0.075 \\
\hline $\begin{array}{l}\text { ATP synthase subunit } \\
\text { alpha }\end{array}$ & AAW33097.1 & 424 & 45498.31 & 7.78 & 45 & 46 & 21110 & 34.86 & 102.85 & 0.024 \\
\hline $\begin{array}{l}\text { 1-aminocyclopropane- } \\
\text { 1-carboxylate oxidase }\end{array}$ & AEX08288.1 & 194 & 22293.55 & 5.26 & 33 & 24 & 24075 & 22.28 & 89.90 & -0.419 \\
\hline Caleosin & ABV72237.1 & 239 & 26975.52 & 5.37 & 30 & 22 & 48360 & 47.02 & 82.09 & -0.265 \\
\hline
\end{tabular}

The computed protein concentration and existence coefficients help in the quantitative study of protein-protein and protein-ligand interactions in solution ${ }^{[15]}$ as well as in the further bioresearch and related product developments. Secondary structure prediction of Ficus pumila proteins by SOPMA revealed that $\alpha$ - helix, random coil, $\beta$ - turn and extended strand were more prevalent. In Oleosin, Glyceraldehyde 3-phosphate dehydrogenase and 1aminocyclopropane-1-carboxylate oxidase, $\alpha$ - helix, which plays a vital role in protein structure and function determination, predominate; whereas in Maturase K, ATP synthase subunit alpha extended strand dominates followed by Beta helix (Table 2). The random coil has dominated in Chitinase and Caleosin proteins of Ficus pumila.

Table 2: SOPMA prediction of Ficus pumila proteins

\begin{tabular}{lcccc}
\hline \multicolumn{1}{c}{ Proteins } & $\begin{array}{c}\text { Alpha helix } \\
(\mathbf{H h})\end{array}$ & $\begin{array}{c}\text { Extended } \\
\text { strand (Ee) }\end{array}$ & $\begin{array}{c}\text { Beta turn } \\
(\mathbf{T t})\end{array}$ & $\begin{array}{c}\text { Random } \\
\text { coil (Cc) }\end{array}$ \\
\hline $\begin{array}{l}\text { NAD(P)H - } \\
\text { quinoneoxidoreductase } \\
\text { subunit5 (ndhF) }\end{array}$ & 33.25 & 21.13 & 4.90 & 40.72 \\
Chitinase & & & & \\
& 21.93 & 14.95 & 5.32 & 57.81 \\
$\begin{array}{l}\text { Oleosin } \\
\text { Glyceraldehyde 3- }\end{array}$ & 45.75 & 15.03 & 9.15 & 30.07 \\
phosphate & 40.35 & 21.93 & 4.39 & 33.33 \\
dehydrogenase (G3pdh) & & & & \\
$\begin{array}{l}\text { Cystatin } \\
\text { Ribulosebisphosphate }\end{array}$ & 39.47 & 16.67 & 4.39 & 39.47 \\
carboxylase (rbcl) & 33.91 & 20.17 & 5.15 & 40.77 \\
$\begin{array}{l}\text { Maturase K } \\
\text { ATP synthase subunit }\end{array}$ & 37.74 & 23.02 & 5.28 & 33.96 \\
alpha (atp1) & 32.31 & 22.64 & 10.61 & 34.43 \\
1-aminocyclopropane-1- \\
carboxylate oxidase
\end{tabular}


The SOSUI predicted the NAD(P)H-quinoneoxido reductase subunit amino acid sequence (length- 461AA) is of a membrane protein which has 6 transmembrane helices which show average hydrophobicity is 0.142082. The TMHMM v.2.0 structure of is shown in Fig. 1. In the case of Glyceraldehyde-3phosphate dehydrogenase, the amino acid sequence (length 189 AA) is of a soluble protein with average hydrophobicity is 0.479365 .

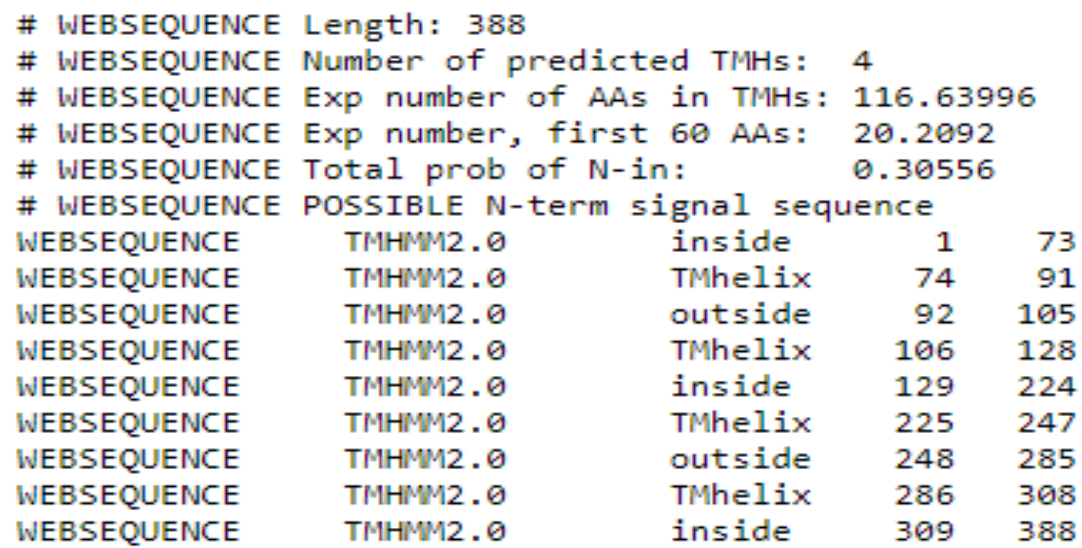

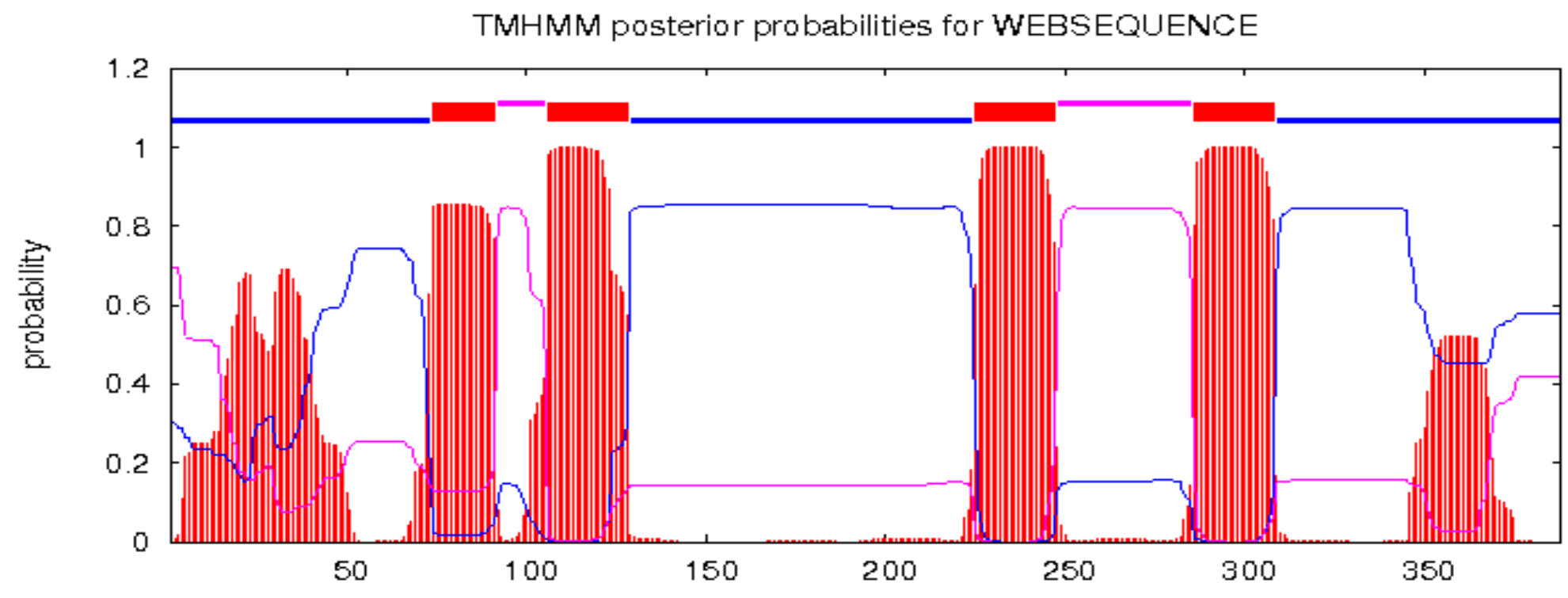

Fig. 1: TMHMM result showing transmembrane region for NAD(P)H-quinone oxidoreductase subunit of Ficus pumila.

Domains are evolutionary units, frequently known as repeated sequences or 3D structures Fig. 2. In our results shows the distribution of the main chain bond lengths and bond angles were found to be inside the limits for these proteins. Such figures assigned by the Ramachandran plot exemplify good quality of the predicted models (Fig. 3). It can determine angles permitted and obtained the insight into the structure of peptides.

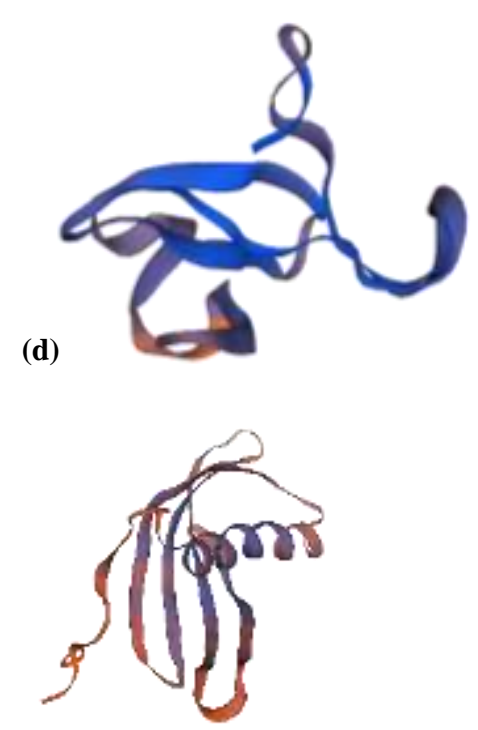

$(\mathbf{g})$

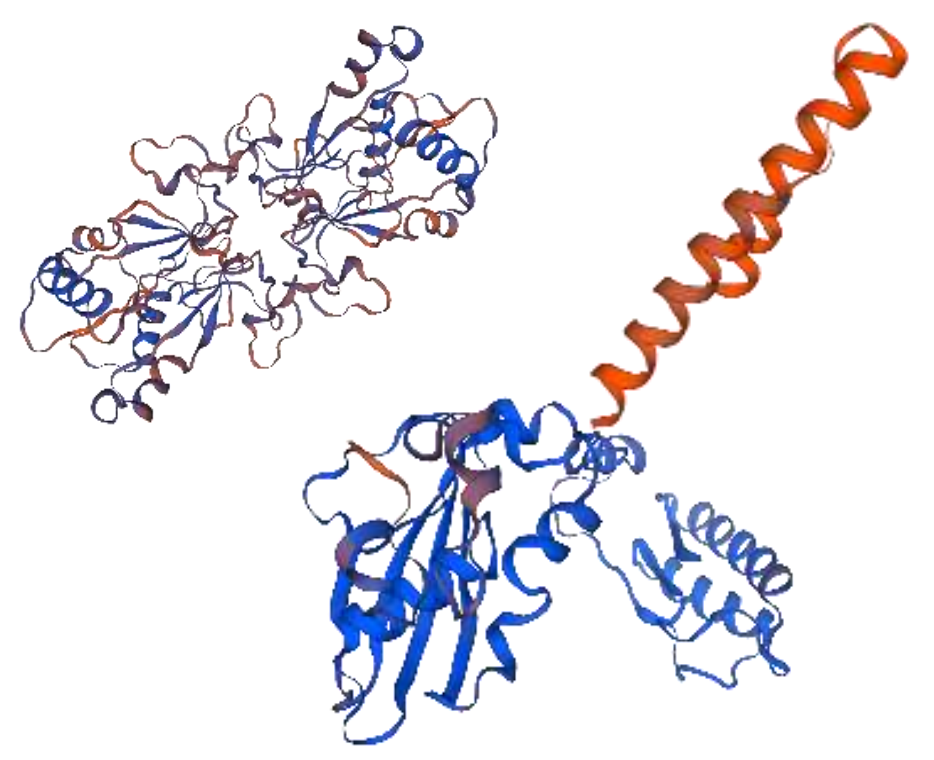

(h) (c) (f)

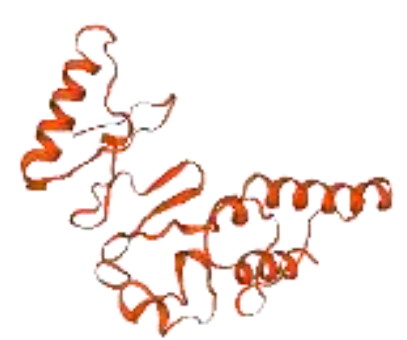

(i)
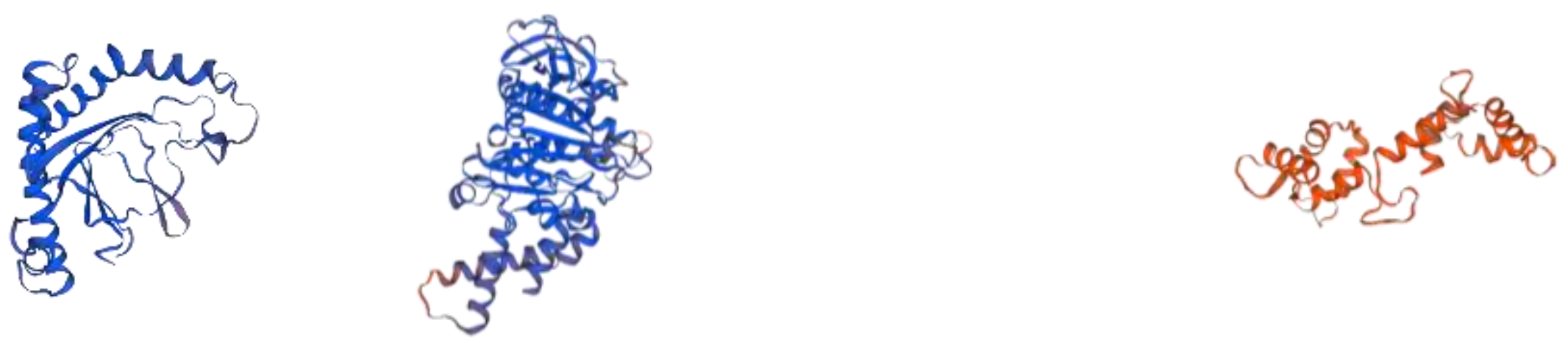

Fig. 2: 3D structure prediction through Swiss Models

a)Chitinase; b)Glyceraldehyde 3-phosphate dehydrogenase; c)Oleosin; d)Cystatin; e)Ribulose bisphosphate carboxylase large chain; f)Maturase K; g)1-aminocyclopropane-1-carboxylate oxidase; h)ATP synthase subunit alpha; i)Caleosin 


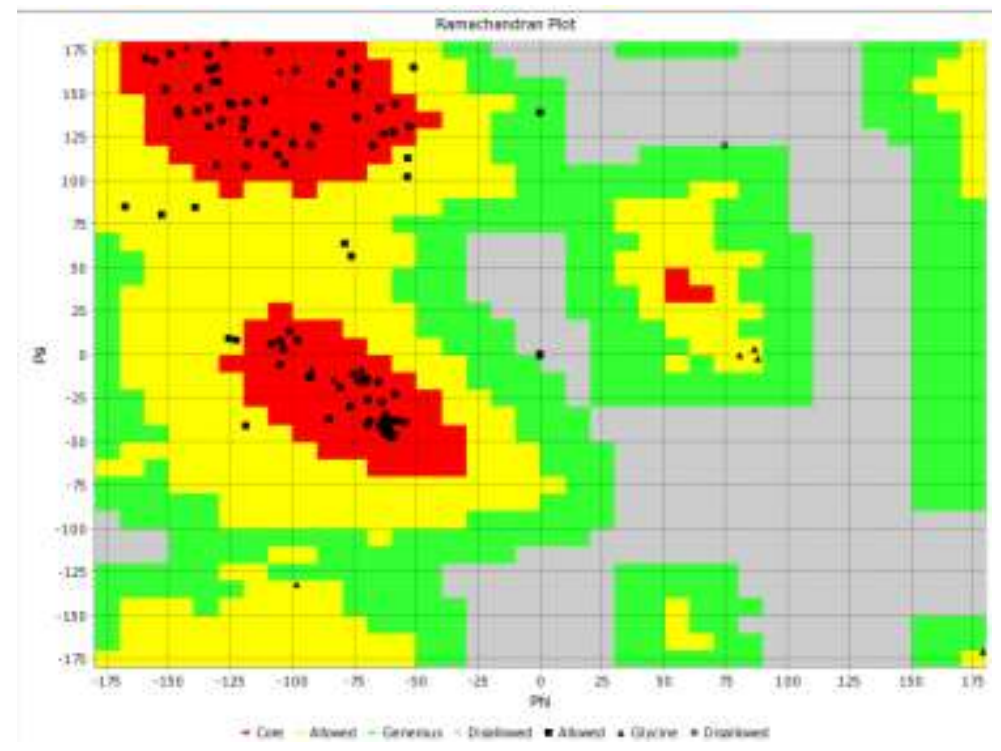

Fig. 3: Ramachandran plot: Glyceraldehyde 3 phosphate dehydrogenase of Ficus pumila

These proteins of Ficus pumila was subjected to BLASTp analysis to find the other plant species having the same query protein. The evolutionary relationship was done with $\mathrm{NAD}(\mathrm{P}) \mathrm{H}$-quinone oxidoreductase subunit and glyceraldehyde-3-phosphophate dehydrogenase proteins. NADPH is an essential cofactor in many metabolic reactions. In plant peroxisomes, several enzyme activities are strictly dependent on the presence of NADPH. NADPH, whose regeneration is critical for reductive biosynthesis and detoxification pathways, is an essential component in cell redox homeostasis and other physiological function of amino acid-producing strains ${ }^{[16]}$.

\section{Role of Predicted pfam domains of the proteins in plants:}

Pfam is a database of such protein domain families, with each family represented by multiple sequence alignments and profile hidden Markov models (HMMs). In addition, each family has associated annotation, literature references and links to other databases. The entries in Pfam are available via the worldwide web and in flat file format. One of the main challenges when constructing such a database is to simultaneously satisfy the conflicting demands of completeness on the one hand and quality of alignment and domain definitions on the other. We have also identified many novel family memberships in known proteins, including new kazal, Fibronectin type III, and response regulator receiver domains. Pfam-A families have permanent accession numbers and form a library of HMMs available for searching and automatic annotation of new protein sequences ${ }^{[17]}$. In the present study, the Pfam domain have located in different position those were tabulated with their E-value (Table 3) and structure (Fig. 4).

Table 3: Predicted Pfam domains of $F$. pumila proteins

\begin{tabular}{|c|c|c|c|c|c|}
\hline $\begin{array}{l}\text { Sl. } \\
\text { No }\end{array}$ & Protein & Pfam Domain & Position & $\begin{array}{c}\text { E- } \\
\text { value }\end{array}$ & Description \\
\hline 1 & Oleosin & Oleosin & $33 \ldots 142$ & & PF01277, Oleosin \\
\hline 2 & Caleosin & Caleosin & $60 \ldots 227$ & & PF05042, Caleosin related protein \\
\hline \multirow[t]{3}{*}{3} & Cystatin & SQAPI & $32 \ldots 111$ & $4.8 \mathrm{e}-35$ & PF16845, Aspartic acid proteinase inhibitor \\
\hline & & Cystatin & $34 \ldots 111$ & $6.2 \mathrm{e}-16$ & PF00031, Cystatin domain \\
\hline & & PP1 & $39 \ldots 104$ & 0.008 & PF07430, Phloem filament protein PPicystatin-like domain \\
\hline \multirow[t]{2}{*}{4} & Chitinase & Glyco_hydro_19 & $89 \ldots 301$ & $4.1 \mathrm{e}-69$ & PF00182, Chitinase class I \\
\hline & & Chitin_bind_1 & $28 \ldots 66$ & $7.4 \mathrm{e}-05$ & PF00187, Chitin recognition protein \\
\hline \multirow[t]{2}{*}{5} & $\mathrm{NdhF}$ & Proton_antipo_C & $124 \ldots 376$ & $\begin{array}{l}2.8 \mathrm{e}- \\
100\end{array}$ & $\begin{array}{l}\text { PF01010, NADH-dehydrogenase subunit F, TMs (complex 1) } \\
\text { C-terminal }\end{array}$ \\
\hline & & Proton_antipo_M & $1 \ldots 118$ & $9.7 \mathrm{e}-31$ & PF00361, Proton-conducting membrane transporter \\
\hline \multirow[t]{2}{*}{6} & Rbc1 & RuBisCO_large & $143 \ldots 451$ & $\begin{array}{l}4.3 \mathrm{e}- \\
128\end{array}$ & $\begin{array}{l}\text { PF00016, Ribulosebisphosphate carboxylase large chain, } \\
\text { catalytic domain }\end{array}$ \\
\hline & & RuBisCO_large_N & $13 \ldots 133$ & $3.4 \mathrm{e}-45$ & $\begin{array}{l}\text { PF02788, Ribulosebisphosphate carboxylase large chain, N- } \\
\text { terminal domain }\end{array}$ \\
\hline 7 & G3pdh & Gp_dh_C & $1 \ldots 120$ & $4.4 \mathrm{e}-55$ & $\begin{array}{l}\text { PF02800, Glyceraldehyde 3-phosphate dehydrogenase, C- } \\
\text { terminal domain }\end{array}$ \\
\hline \multirow[t]{3}{*}{8} & atp1 & ATP-synt_ab & $121 \ldots 345$ & $2.3 e-71$ & $\begin{array}{l}\text { PF00006, ATP synthase alpha/beta family, nucleotide-binding } \\
\text { domain }\end{array}$ \\
\hline & & ATP-synt_ab_C & $352 \ldots 424$ & $2.3 e-33$ & PF00306, ATP synthase alpha/beta family, C terminal domain \\
\hline & & ATP-synt_ab_N & $1 \ldots 64$ & $2.3 e-18$ & PF02874, ATP synthase alpha/beta family, beta-barrel domain \\
\hline \multirow[t]{2}{*}{9} & Acol & 2OG-FeII_oxy & $131 \ldots 193$ & $2.3 e-15$ & PF03171, 2OG-Fe(II) oxygenase superfamily \\
\hline & & DIOX_N & $1 \ldots 39$ & $6.5 \mathrm{e}-06$ & $\begin{array}{l}\text { PF14226, non-haemdioxygenase in morphine synthesis N- } \\
\text { terminal }\end{array}$ \\
\hline
\end{tabular}




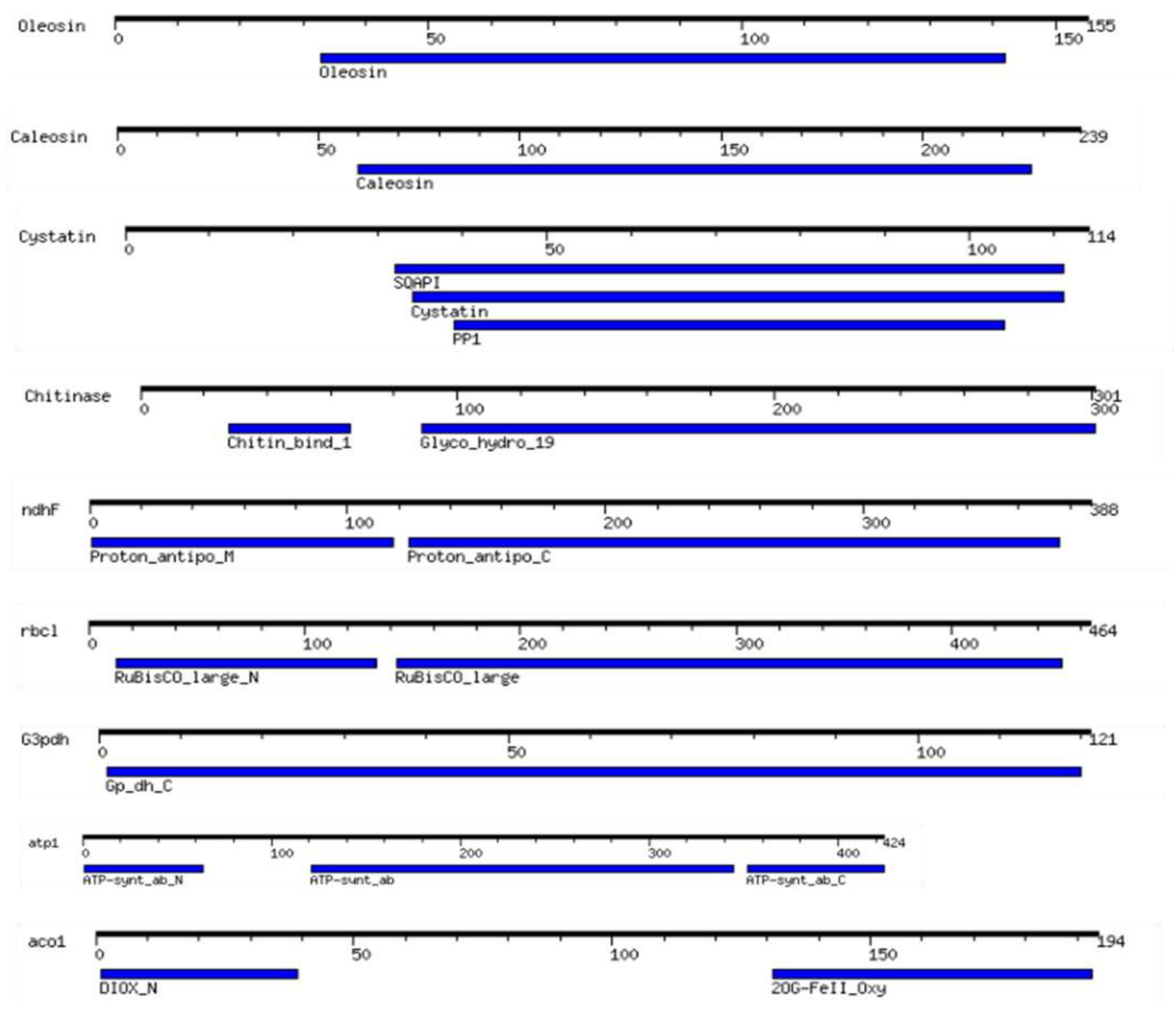

Figure 4: Predicted pfam domains of the proteins

The Glyceraldehyde-3-phosphate dehydrogenase involving plant metabolism and evidence that the complex interactions existing between metabolism and development. Glyceraldehyde-3-phosphate dehydrogenase (NAD-GAPDH) is involved in a critical energetic step of glycolysis and also has several significant functions moreover its enzymatic activity ${ }^{[18,19]}$. It showed resemblances with 21 plants from 13 families where 6 plants from Brassicaceae which possess $94-$ 96\% identity shows the true relationship with Ficus pumila. The whole tree indices the identity ranges from 93.9 to $98.2 \%$. It was also traced with higher identity (95.6\%) with families such as Solanaceae, Rosaceae and Lamiaceae. The plant Arachishypogaea show 98\% identity and Vigna angularis shows $94.7 \%$, therefore two plants are in the nearest relationship in Leguminosae family. This finding suggests that Ficus pumila and closely related plants of different families listed here may evolved from a common ancestor. Merging and separation are two distinguished phylogenetic properties, which can be valuable to determine uniqueness, closely as well as distantly related group of protein sequences ${ }^{[20]}$. Glyceraldehyde-3- phosphate dehydrogenase protein sequences of Diplocyclos palmatus are almost coincidences with the known plant protein sequences of Euphorbiaceae, and Araliaceae with the identity of more than $95 \%{ }^{[21]}$.

It showed resemblances with ten families of twelve plant species ranges from 74 to $94 \%$. It was traced in families such as Rosaceae, Solanaceae and Moraceae (own family). It indicates the phylogeny of the plant with the families mostly up to above 90\% identity followed by Rutaceae, Asteraceae and Brassicaceae shows the identity of 87-89\%. It shows $90.8 \%$ identity with the own family member Morus indica proved the true relationship with Ficus pumila. The phylogenetic tree of NAD(P)H-quinoneoxidoreductase subunit of the plants is presented in Table 4 \& Fig. 5. In present study the Glyceraldehyde-3phosphate dehydrogenase protein sequences of $F$. pumila shows the resemblance with Leguminosae, Brassicaceae, Solanaceae and Rosaceae families ranges from 95-98\% predominantly (Table 5 \& Fig.6). 
Table 4: Phylogeny of Ficus pumila traced through NAD(P)H-quinone oxidoreductase subunit

\begin{tabular}{llll}
\hline $\begin{array}{c}\text { Accession } \\
\text { No }\end{array}$ & \multicolumn{1}{c}{$\begin{array}{c}\text { Plant species containing } \\
\text { NAD(P)H-quinoneoxidoreductase } \\
\text { subunit protein }\end{array}$} & \multicolumn{1}{c}{ Family } & $\begin{array}{c}\text { Identity } \\
\mathbf{\%}\end{array}$ \\
\hline ABB21003.1 & Morusindica & Moraceae & $\mathbf{9 0 . 8}$ \\
ESR41467.1 & Citrus clementina & Rutaceae & 87.2 \\
PRQ15668.1 & Rosa chinensis & Rosaceae & $\mathbf{9 3 . 1}$ \\
OTG25873.1 & Helianthus annuus & Asteraceae & 87.8 \\
EFH44954.1 & Arabidopsis lyrata & Brassicaceae & 88.4 \\
TYJ27490.1 & Gossypiummustelinum & Malvaceae & 86.8 \\
OIT27308.1 & Nicotianaattenuata & Solanaceae & $\mathbf{9 2 . 3}$ \\
RYQ84036.1 & Arachishypogaea & Leguminosae & 86.9 \\
RXI09703.1 & Malusdomestica & Rosaceae & $\mathbf{9 2 . 2}$ \\
PUZ60784.1 & Panicumhallii var. hallii & Poaceae & 79.5 \\
ADO65021.1 & Prunuspersica & Rosaceae & 74.1 \\
AAT98557.1 & Panax ginseng & Araliaceae & 74.0 \\
\hline
\end{tabular}

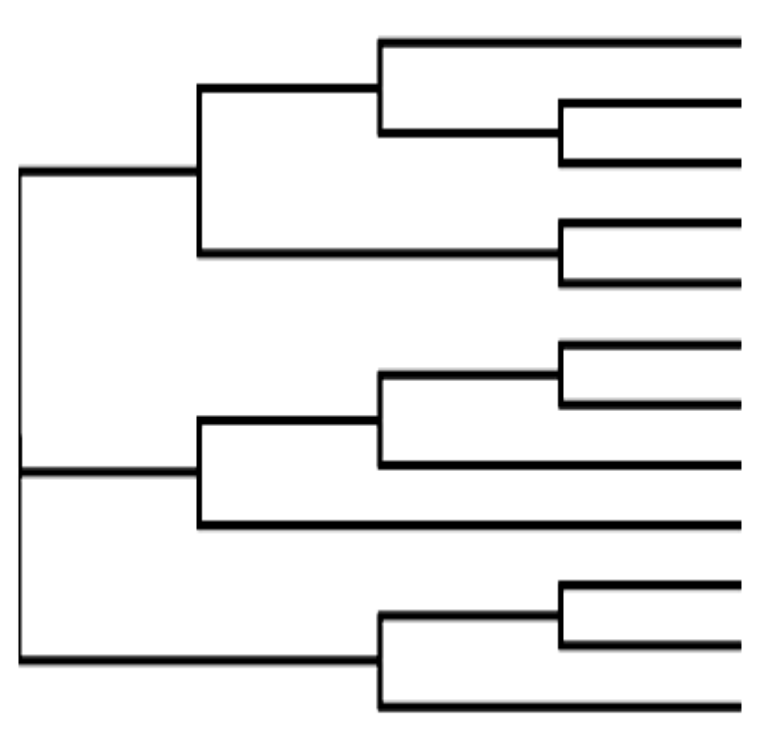

Panicum 0.13465

Citrus 0.07272

Arachis 0.0964

Arabidopsis 0.04936

Morus 0.07046

Malus 0.0826

Prunus 0.02782

Rosa 0.03072

Gossypium 0.0574

Helianthus 0.02841

Panax 0.03953

Nicotiana 0.01294

Fig. 5: Phylogenetic tree of Ficus pumila traced through NAD(P)H-quinone oxidoreductase subunit

Table 5: Phylogeny of Ficus pumila traced throughglyceraldehyde-3-phosphate dehydrogenase protein

\begin{tabular}{llll}
\hline Accession No & $\begin{array}{l}\text { Plant species containing } \\
\text { glyceraldehyde-3-phosphate } \\
\text { dehydrogynase protein }\end{array}$ & Family & $\begin{array}{l}\text { Similarity } \\
\%\end{array}$ \\
\hline RYR67635.1 & Arachishypogaea & Leguminosae & 98.2 \\
CAA7039284.1 & Microthlaspierraticum & Brassicaceae & 96.5 \\
PHU23654.1 & Capsicum chinense & Solanaceae & 95.6 \\
CDY42906.1 & Brassica napus & Brassicaceae & 95.6 \\
ESQ35475.1 & Eutremasalsugineum & Brassicaceae & 95.6 \\
EFH69008.1 & Arabidopsis lyrata & Brassicaceae & 95.6 \\
ONI08055.1 & Prunuspersica & Rosaceae & 95.6 \\
TEY91672.1 & Salvia splendens & Lamiaceae & 95.6 \\
KFK37847.1 & Arabisalpina & Brassicaceae & 95.6 \\
KZM93169.1 & Daucuscarota & Apiaceae & 94.7 \\
PKI77035.1 & Punicagranatum & Lythraceae & 94.7 \\
KAB2624871.1 & Pyrusussuriensis & Rosaceae & 94.7 \\
KCW61990.1 & Eucalyptus grandis & Myrtaceae & 94.7 \\
BAT79321.1 & Vignaangularis & Leguminosae & 94.7 \\
EOA38185.1 & Capsella rubella & Brassicaceae & 94.7 \\
PLY75941.1 & Lactucasativa & Asteraceae & 94.7 \\
RXH96054.1 & Malusdomestica & Rosaceae & 94.7 \\
PSS30165.1 & Actinidiachinensis & Actinidiaceae & 94.7 \\
KNA16142.1 & Spinaciaoleracea & Amaranthaceae & 94.7 \\
PIA51356.1 & Aquilegia coerulea & Ranunculaceae & 94.7 \\
KDO82023.1 & Citrus sinensis & Rutaceae & 93.9 \\
\hline
\end{tabular}




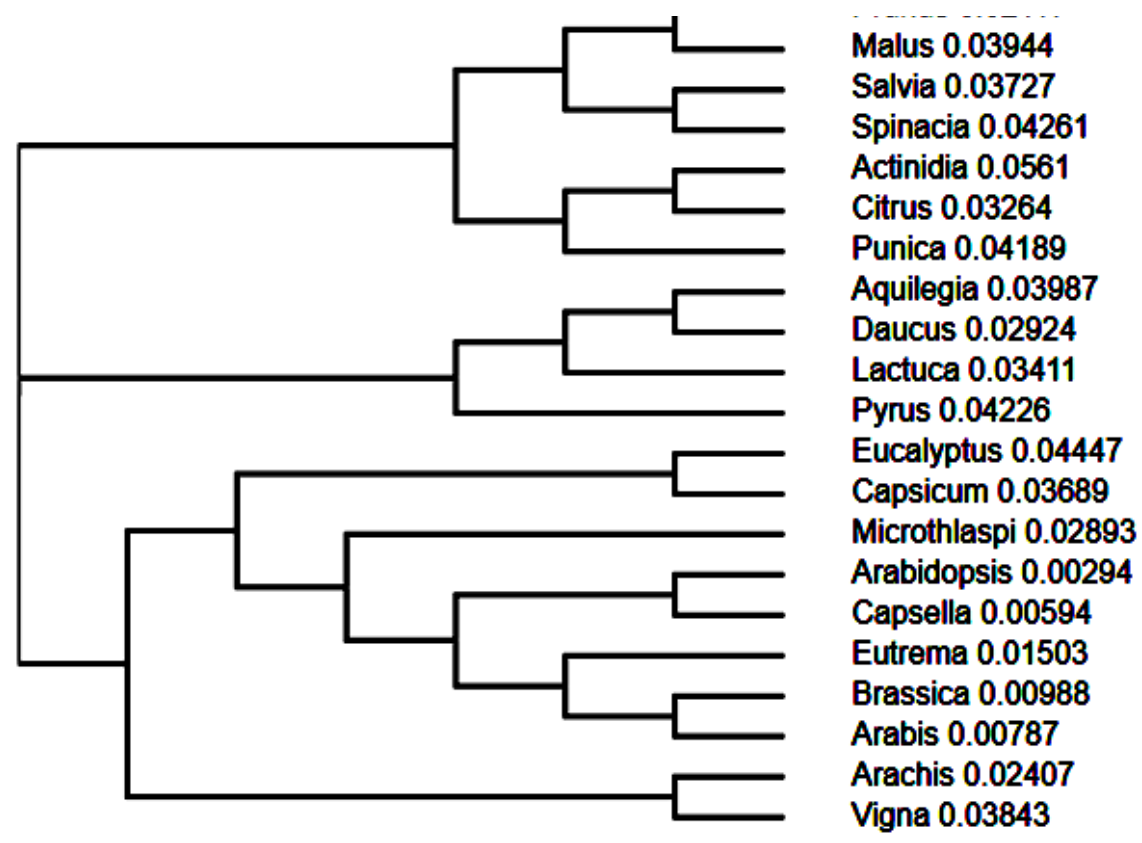

Fig. 6: Phylogenetic tree of Ficus pumila traced through glyceraldehyde-3-phosphate dehydrogenase protein

The selected proteins in $F$. pumila have extensive and scientifically proved pharmacological potent hence, the plant can be used to target different health concerns and can be used in pharmaceutical inventions and drug development researches.

\section{CONCLUSION}

Mapping the physicochemical characters of plant proteins and their relationship with other families will provide an important guideline for the future study of plant biology and drug development. Physicochemical characters of various proteins of Ficus pumila have been analysed and their three dimensional structure were predicted. Multiple alignments are a central feature of Pfam. The web sites provide access to the seed and full alignments in a variety of formats, allowing users to input Pfam data into their own software. Alignments are best viewed with specialised programs that can highlight similar regions and carry out manipulations of the alignment. The phylogeny of the plant proteins NAD(P)H-quinone oxidoreductase and Glyceraldehyde-3-phosphate dehydrogenase were traced by their relationships with other plants. The results suggested that the selected proteins having unique characters as well as the phylogeny indicate the convergence and divergence with different plants of different families even through the long history of evolution. Further, phytochemicals and the peptides of the proteins will be used for further studies to assess their potential biological activity in targeting various diseases. This team will carry these biomaterials to explore the many therapeutic properties in future for the drug target identification.

\section{Acknowledgements}

We are thankful to the Secretary and Director Dr. C. A. Vasuki, Kongunadu Arts and Science College for her fullest encouragement and support

\section{REFERENCES}

1. Jasreet Kaur. "Pharmacognostical and Preliminary Phytochemical Studies on the Leaf Extract of Ficus pumila Linn." Journal of Pharmacognsy and Phytochemistry Vol. 1, no.4, (2012), pp. 105.

2. K Nirubama, RT Narendhirakannan, G Rubalakshmi, N Vijayakumar, M Vinodhini. "Research Article Homology Modeling and Insilico Approach of Cleome gynandra - An Indigenous Medicinal Plant”. Kongunadu Research Journal. Vol.7, no.2, (2020), pp. 1-6.

3. Manuela Pruess, Rolf Apweiler. "Bioinformatics Resources for In Silico Proteome Analysis". Journal of Biomedicine and Biotechnology. Vol.2003 (4), (2003), pp. 231-236.

4. Ubaid Yaqoob, Tanushri Kaul, Irshad Ahmad Nawchoo. "In-Silico Analysis, Structural Modelling and Phylogenetic Analysis of Acetohydroxy acid Synthase Gene of Oryza sativa”. Med Aromat Plants (Los Angel). Vol. 5, (2016), pp. 1-6.

5. Singapore Government-National Parks Board. "Ficus pumila L. - flora and fauna web". A Singapore Government Agency (2019). Website. Available at. https://www.nparks.gov.sg/florafaunaweb/flora/1/4/1403.

6. V Dao, I Langella, J Carbo. "From green to sustainability: Information Technology and an integrated sustainability framework". Journal of Strategic Information Systems, Vol. 20(1), (2011), pp. 63-79.

7. E Gasteiger, C Hoogland, A Gattiker, S Duvaud, MR Wilkins, RD Appel, A Bairoch. "Protein Identification and Analysis Tools on the EXPASY Server". The Proteomics Protocols Handbook, (In) John M. Walker (ed). Humana Press, Vol.10, (2005), pp.571-607.

8. G Perriere, M Gouy. WWW-Query: An on-line retrieval system for biological sequence banks. Biochimie Vol.78, (1996), pp. 364-369.

9. Upgade Akhilesh, Bhaskar, Anusha, Issar Sakshi, Senthamarai Selvi V. In Silico Characterization of Keratitis Causing Herpes Simplex Virus (HSV 1) Membrane Proteins using Computational Tools and Servers. Research Journal of Recent Science. Vol. 1(11), (2012), pp. 27-31.

10. C Bézivin, F Tomasi, F Lohézic-Le Devehat, J Boustie. "Cytotoxic activity of some lichen extracts on murine and human cancer cell lines". Phytomed. Vol. 10, (2003), pp. 499-503.

11. G Anbarasi, B Vishnupriya. "Molecular identification and phylogenetic analysis of Suaeda Maritima from Parangipettai coastal areas, southeast coast of India". Kongunadu Research Journal, Vol. 7(1), (2020), pp.28-34.

12. GE Hutchinson, JK Setlow, JL Brooks. "Biochemical observations on Asterias forbesi, Studies on the marine resources of sourthern New England. III the possibility of the utilization of starfish (Asterias forbesi desor), Bulletin of the Bingham Bingham Oceanographic collection". Peabody Museum of Natural History Yale University. Bingham Oceanographic Laboratory, New Haven, Conn., U.S.A, (1946). 
13. Kebila Venkatasamy. "In silico Analysis and Homology Modeling of Putative Hypothetical Protein Q4QH83 of Leishmania major". Advanced BioTech., Vol. 13(3), (2013), pp. 1-4.

14. T Shohaib, M Shafique, N Dhanya, Madhu C Divakar. "Importance of flavonoides in therapeutics". Hygeia J D Med., Vol. 3(1), (2001), pp. 1-18.

15. SC Gill, PH von Hippel. "Calculation of protein extinction coefficients from amino acid sequence data". Anal Biochem., Vol. 182(2), (1989), pp. 319326.

16. AD Fernández-Fernández, Francisco J. Corpas. "In Silico Analysis of Arabidopsis thaliana Peroxisomal 6-Phosphogluconate Dehydrogenase". Scientifica Vol. 2016, (2016), pp.1-9.

17. EL Sonnhammer, SR Eddy, R Durbin. "Pfam: a comprehensive database of protein domain families based on seed alignments". Proteins. Vol. 28(3), (1997), pp.405-20.

18. J Muñoz-Bertomeu, B Cascales-Miñana, M Alaiz, J Segura, R Ros. "A critical role of plastidial glycolytic glyceraldehyde-3-phosphate dehydrogenase in the control of plant metabolism and development". Plant Signal Behav. Vol. 5(1), (2010), pp. 67-9.

19. CV Piattoni, DML Ferrero, I Dellaferrera, A Vegetti, AÁ Iglesias. "Cytosolic Glyceraldehyde-3-Phosphate Dehydrogenase is phosphorylated during seed development". Front Plant Sci. Vol. 8, (2017), pp. 522.

20. P Vadnere Gautam, R Pathan Aslam, U Kulkarni Bharti, Abhay Kumar Singhai. "Diplocyclos Palmatus: A Phytopharmacological Review”. Int J Res Pharm Chem., Vol. 3, (2013), pp.157-159.

21. WW Zhang, LI McCall, G Matlashewski. "Role of cytosolic glyceraldehyde-3-phosphate dehydrogenase in visceral organ infection by Leishmania donovani." Eukaryotic cell vol. 12, no.1 (2013), pp. 70-7. 